\title{
Laparoscopic versus open distal gastrectomy for locally advanced gastric cancer in middle-low-volume centers in Western countries: a propensity score matching analysis
}

\author{
Giovanni Maria Garbarino ${ }^{1,2}$ (D) - Gianluca Costa ${ }^{1}$ - Giovanni Guglielmo Laracca ${ }^{1,2}$ - Giorgio Castagnola ${ }^{1}$ \\ Paolo Mercantini ${ }^{1} \cdot$ Massimiliano Di Paola $^{2} \cdot$ Simone Vita $^{2} \cdot$ Luigi Masoni $^{1,2}$
}

Received: 15 May 2020 / Accepted: 27 July 2020 / Published online: 4 August 2020

(C) The Author(s) 2020

\begin{abstract}
Background Gastrectomy with D2 lymphadenectomy is the standard treatment for patients with resectable gastric cancer. Laparoscopic distal gastrectomy (LDG) is routinely performed for early gastric cancer, and its indications are increasing even for locally advanced gastric cancer. The aim of this study is to compare two middle-low-volume centers in Western countries experience on LDG versus open distal gastrectomy (ODG) for locally advanced gastric cancer in terms of surgical and oncological outcomes.

Methods We reviewed the data of 123 consecutive patients that underwent LDG and ODG with D2 lymphadenectomy between 2009 and 2014. Among them, 91 were eligible for inclusion (46 LDG and 45 ODG). After propensity score matching analysis, using a 1:1 case-control match, 34 patients were stratified for each group.

Results The mean operative time was significantly longer in the LDG group (257.2 vs. 197.2, $p<0.001)$. No differences were observed in terms of intraoperative blood loss, average number of lymph nodes removed, and lymph node metastases. The postoperative morbidity was comparable in the two groups. LDG group had a significant faster bowel canalization and soft oral intake $(p<0.001)$. The 5 -year overall and disease-free survival were higher for patients treated by laparoscopy, but the post-hoc subgroups analysis revealed that the advantage of LDG was significant just in N0 and stage IB-II patients, whereas N+ and stage III patient's survival curves were perfectly superimposable.

Conclusions LDG for locally advanced gastric cancer seems to be feasible and safe with surgical and long-term oncological outcomes comparable with open surgery, even in medium-low-volume centers.
\end{abstract}

Keywords Gastric Cancer $\cdot$ Laparoscopic surgery $\cdot$ Postoperative recovery $\cdot$ Long-term oncological outcomes $\cdot$ Middlelow-volume centers

\section{Introduction}

Gastric cancer represents the fifth most common cancer in the world and the third leading cause of cancer death. In Europe, where no screening programs are foreseen, the diagnosis

Giovanni Maria Garbarino

giovannimaria.garbarino@uniroma1.it

1 Department of Medical Surgical Science and Translational Medicine, Sant'Andrea Hospital, Sapienza University of Rome, Via di Grottarossa 1035-39, 00189 Rome, Italy

2 Genaral Surgery Department, San Pietro Fatebenefratelli Hospital, Via Cassia 600, 00189 Rome, Italy usually occurs at an advanced stage and 5-year survival is reported at around $25 \%[1,2]$.

Total or distal gastrectomy based on the location of the disease associated with D2 lymphadenectomy is the standard treatment for patients with resectable disease (stage IB-III) [3, 4].

For the treatment of locally advanced gastric cancer, a D2 lymphadenectomy is mandatory and it is recommended to be conducted by experienced surgeons in high-volume centers, especially if performed laparoscopically [5-7].

The traditional open surgical approach still represents the most widespread surgical technique.

Since the first laparoscopic distal gastrectomy has been described by Kitano [8], the technique has widely spread, especially in Eastern countries, where several randomized 
controlled trials (RCTs) have demonstrated better short-term results than open surgery and comparable overall and diseasespecific survival rates for the treatment of early gastric cancer, with [9-11].

The Japanese gastric cancer treatment guidelines described, for the first time in 2014 (ver. 4), the laparoscopic distal gastrectomy (LDG) as one treatment option in general practice for stage I gastric cancer (T1N0M0, T1N1M0, or T2aN0M0) [3].

Nowadays, the indications for LDG are constantly increasing, even for locally advanced gastric cancer, as shown by the short-term results of the Eastern countries multicentric RCTs $[10,12,13]$.

Recently, the CRITICS trial results showed that highvolume centers $(\geq 21$ procedures per year) were associated with higher both overall and disease-free survival, emphasizing the value of centralizing gastric cancer surgeries even in the Western world [14]. Conversely, some Korean studies revealed that LDG in low-volume centers is feasible and safe; nonetheless, the early surgical outcomes of LDG performed by the same surgeon in two different volume centers seems to be better when carried out in the high-volume one [15-17].

The aim of this study is to compare LDG and ODG with D2 lymphadenectomy for locally advanced gastric cancer in terms of surgical safety and feasibility, postoperative outcomes, and long-term oncological outcomes in the setting of a middle-low-volume center.

\section{Methods}

\section{Patient's selection}

This was a retrospective case-matched observational study including all consecutive patients undergoing surgery for locally advanced gastric cancer (cT2-T4a, cN0-N3, M0). The exclusion criteria were $\mathrm{cT} 1$ and $\mathrm{cT} 4 \mathrm{~b}$ gastric cancer, metastatic patients, and patients treated by neoadjuvant chemotherapy [Fig. 1]. Distal gastrectomy with D2 lymphadenectomy was performed by two senior staff surgeons (L.M. and S.V.) with large experience in minimally invasive surgery at the Department of General Surgery of San Pietro Fatebenefratelli Hospital and Sant'Andrea Hospital in Rome, between 2009 and 2014.

Indications for surgery were defined on a histologically proven gastric adenocarcinoma of the antro-pyloric region or distal body of the stomach, pre-operative CT staging, anaesthesiologist, and multidisciplinary team evaluation (oncologist, surgeon, radiotherapist, gastroenterologist, pathologist, and radiologist).

Adjuvant chemotherapy (oxaliplatin and capecitabine) was administered according to the "Associazione Italiana di Oncologia Medica" (AIOM) guidelines at time of the surgical treatment (www.aiom.it).
Data was retrospectively reviewed from prospectively maintained database. Data included demographic variables, tumor characteristics and management, operative data, tumor pathology, and short- and long-term outcomes.

Patients were divided into two groups according to the surgical approach: laparoscopic (LDG) and open (ODG) distal gastrectomy.

This study was conducted in accordance with the Declaration of Helsinki and its later amendments. A formal Institutional Review Board approval was not required because of the non-interventional retrospective design; however, a signed consent for the treatment and the analysis of data for scientific purpose was obtained from all patients before any surgical procedures.

\section{Surgical technique}

\section{Laparoscopic distal gastrectomy}

The patient is placed on the operating table in the French position, with the primary surgeon placed between the legs of the patient, the first assistant on the right side of the patients, and the second assistant on the left side.

Under general anesthesia, $12 \mathrm{mmHg}$ pneumoperitoneum was induced with open laparoscopy approach. Four or five trocars were inserted in the upper abdomen. The first step consisted into the exploration of the abdominal cavity, aimed at excluding the presence of ascites, peritoneal carcinosis, or any metastasis, not identified preoperatively and performing the peritoneal lavage, as previously described [18]. Therefore, the liver, the mobility or the fixity of the gastric lesion, the epiploon, the colon, and the transverse mesocolon are explored to detect any metastases or neoplastic infiltrations. Once the effective resectability of the neoplasm has been established, the operative technique was similar to open surgery: colon-epiploic dissection, access to the epiploon retrocavity, dissection, ligation and section of the right gastroepiploic vessels, section of the hepatoduodenal ligament, followed by ligation, and section of the right gastric vessels. Then the duodenum was divided using a $60-\mathrm{mm}$ endoscopic linear stapler and a D2 lymphadenectomy $(1,3,4 \mathrm{sb}$, $4 \mathrm{~d}, 5,6,7,8 \mathrm{a}, 9,11 \mathrm{p}, 12 \mathrm{a})$ was carried out en bloc with the specimen with the ligation and section of the left gastric vessels. Gastric resection was performed using a $60-\mathrm{mm}$ endoscopic linear stapler. The resected specimen is placed in a plastic bag and removed preferentially enlarging a $12 \mathrm{~mm}$ port. This incision can be used to perform the extracorporeal jejunojejunal anastomosis. Then the abdomen is reinsufflated to perform the laparoscopic Roux en Y gastro-jejunal anastomosis, using a $60-\mathrm{mm}$ endoscopic linear stapler. The enterotomy is closed with a $3 / 0$ absorbable self-locking suture.

The anastomosis can be performed either antecolic or transmesocolic, according to surgeon's preference. 
Fig. 1 Clinical study design and propensity score method

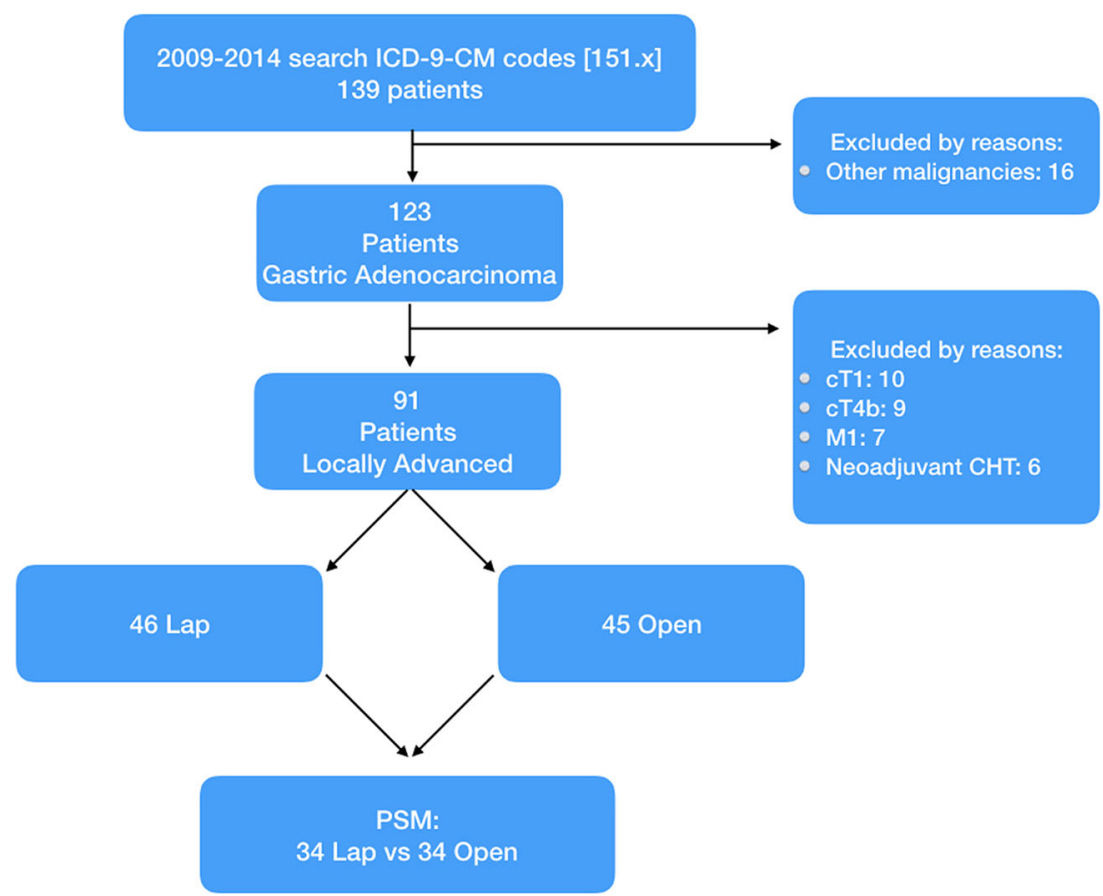

Abdominal drainages are placed through the trocar orifices: one close to the duodenal stump and the other posterior to the gastrojejunal anastomosis.

\section{Open gastrectomy}

The patient is placed on the operating table in supine position, closed legs, and arms along the body.

The primary surgeon is positioned to the right side of the patient, the first assistant in front of the surgeon, and the second assistant on the left side of the primary surgeon.

The same steps as for laparoscopic approach were carried out through a midline xifo-umbilical laparotomy. Usually, a transmesocolic gastrojejunal Roux en Y anastomosis was performed with a 60-mm linear stapler and a jejunojejunal anastomosis was performed manually in single layer.

Abdominal drainages are placed close to the duodenal stump and posterior to the gastrojejunal anastomosis.

\section{Study criteria}

Tumor staging was performed according to 7 th TNM edition [19]. Pathological data also included the completeness of resection, the lymph node harvest (LNH), and the lymph node ratio (LNR).

Morbidity and mortality were respectively defined as postoperative complications and death within 90 days after surgery. Postoperative morbidity was graded according to the Clavien-Dindo classification [20], in which grade III and IV were defined as "major complications." Reoperation was defined as every surgical procedure following primary surgery during hospitalization or within 30 days after primary intervention.

\section{Statistical analysis}

The patient baseline characteristics were expressed as the mean ( \pm standard deviation) or median (range) for continuous data and as numbers with percentages for categorical data. Comparison of categorical variables was performed using the $\chi^{2}$ test or Fisher's exact test with Yates correction when appropriate. Unpaired Student $t$ test was used to compare differences in continuous parametric variables and the MannWhitney $U$ test for continuous nonparametric variables when appropriate.

In order to compare perioperative and oncological outcomes of laparoscopic and open surgery for gastric cancer, we performed a propensity score matching analysis.

Propensity scores were calculated by bivariate logistic regression, including the following variables that might be considered as potential baseline confounders between the groups: age, Sex, BMI, ASA score, comorbidity, histotype. The exact matching for $\mathrm{N}$ stage was also applied. We matched propensity scores 1:1 with the use of the nearest neighbor methods without replacement by using a 0.3 calipers width to achieve the maximum number of cases without statistical differences in confounders variables.

Survival analyses were conducted using the Kaplan-Meier method with log-rank test and Cox regression analysis. Significance was defined as a $p$ value of less than 0.05 . The statistical analysis was performed using the SPSS version 25.0 (SPSS, Inc., Chicago, IL). 


\section{Results}

\section{Patients' characteristics}

In our study, a total of 123 patients underwent LDG or ODG for gastric adenocarcinoma. Sixty patients were treated with a laparoscopic approach; the other 63 were treated with a laparotomic approach. Of these, 91 patients were eligible for the study because they were affected by locally advanced disease (cT2-4a cN0-3M0): 46 patients underwent LDG and 45 ODG. Patients with cT1, cT4b, metastatic disease, or treated by neoadjuvant chemotherapy were excluded from the study.

Demographic characteristics are shown in Table 1.

After propensity score matching, two groups of 34 patients, perfectly superimposable as regards the $\mathrm{N}$ stage and homogeneous for sex, age, BMI, ASA score, comorbidities, histotype, and tumor size, were extracted.

\section{Intraoperative characteristics and postoperative outcomes}

The intraoperative characteristics and postoperative outcomes are shown in Table 2. Conversion during LDG occurred in 5 $(14.7 \%)$ patients: because of tumor infiltration of the pancreatic capsule or anterior layer of transverse mesocolon (3 patients) and to obtain a correct surgical exposition (2 patients).
The only death occurred as a result of postoperative hemoperitoneum on postoperative day (POD) 1 after LDG for a stage IIIb gastric cancer. The patient underwent reoperation by laparotomy but then developed heart failure.

Briefly, statistical differences were found in the time of surgery (257.2 \pm 46.3 vs. $197.2 \pm 66.4 \mathrm{~min}, p \leq 0.001)$, time to first flatus ( $4.1 \pm 1.5$ vs. $5.6 \pm 1.5$ days, $p \leq 0.001)$, and time to soft oral intake $(4.8 \pm 1.5$ vs. $7.5 \pm 4.8$ days, $p \leq 0.001)$.

Even if an advantageous trend has been observed for the laparoscopic approach, no statistical differences were recorded about blood loss (140.8 \pm 170.9 vs. $180.3 \pm 165.3 \mathrm{~mL}, p=$ $0.217)$ and time of hospital stay $(11.8 \pm 8.3$ vs. $15.8 \pm$ 13.7 days, $p=0.120)$.

Focusing on the postoperative morbidity, there were no statistical differences between the two groups. Furthermore, the patients treated by open approach developed a higher rate of major complications with the need of reoperation $(5.9 \%$ vs. $17.6 \%, p=0.132$ ).

\section{Pathological and long-term postoperative outcomes}

The pathological outcomes are shown in the Table 3. All cytological examinations performed on the peritoneal lavage resulted as negatives. TNM stage $(p=0.392)$, the number or retrieved lymph nodes (24.5 vs. $24.0, p=0.849)$, and R0 resection $(100 \%$ vs. $94.4 \%, p=0.473)$ were comparable between the two groups. As a result of the propensity score

Table 1 Demographics characteristics before and after propensity score matching analysis

\begin{tabular}{|c|c|c|c|c|c|c|}
\hline & \multicolumn{3}{|c|}{ Before propensity score matching } & \multicolumn{3}{|c|}{ After propensity score matching } \\
\hline & $\begin{array}{l}\text { ODG } \\
n=45\end{array}$ & $\begin{array}{l}\mathrm{LDG} \\
n=46\end{array}$ & $p$ & $\begin{array}{l}\text { ODG } \\
n=34\end{array}$ & $\begin{array}{l}\text { LDG } \\
n=34\end{array}$ & $p$ \\
\hline AGE (years, mean, $\pm \mathrm{SD}$ ) & $72.1( \pm 10.1)$ & $72.2( \pm 9.9)$ & 0.937 & $71.1( \pm 9.1)$ & $70.9( \pm 10.7)$ & 0.951 \\
\hline $\operatorname{SEX}(n, \%)$ & & & 0.608 & & & 0.612 \\
\hline M & $26(57.8 \%)$ & $29(63.0 \%)$ & & $21(61.8 \%)$ & $23(67.6 \%)$ & \\
\hline $\mathrm{F}$ & $19(42.2 \%)$ & $17(37.0 \%)$ & & $13(38.2 \%)$ & $11(32.4 \%)$ & \\
\hline $\mathrm{BMI}($ mean, $\pm \mathrm{SD}$ ) & $23.3( \pm 3.7)$ & $24.2( \pm 3.8)$ & 0.266 & $24.2( \pm 3.2)$ & $24.2( \pm 4.1)$ & 0.932 \\
\hline $\operatorname{ASA} \operatorname{SCORE}(n, \%)$ & & & 0.063 & & & 0.746 \\
\hline 1 & $5(11.1 \%)$ & $1(2.2 \%)$ & & $1(2.9 \%)$ & $1(2.9 \%)$ & \\
\hline 2 & $16(35.6 \%)$ & $14(30.4 \%)$ & & $14(41.2 \%)$ & $10(29.4 \%)$ & \\
\hline 3 & $23(51.1 \%)$ & $24(52.2 \%)$ & & $18(52.9 \%)$ & $21(61.8 \%)$ & \\
\hline 4 & $1(2.2 \%)$ & $7(15.2 \%)$ & & $1(2.9 \%)$ & $2(5.9 \%)$ & \\
\hline Comorbidity ( $n$ pts, $\%$ ) & $38(84.4 \%)$ & $37(80.4 \%)$ & 0.615 & $30(88.2 \%)$ & $30(88.2 \%)$ & 1.000 \\
\hline Associated disease $(n, \%)$ & & & 0.734 & & & 0.994 \\
\hline Cardiovascular & $26(57.7 \%)$ & $27(58.7 \%)$ & & $20(58.8 \%)$ & $18(52.9 \%)$ & \\
\hline Respiratory & $11(24.4 \%)$ & $9(20.0 \%)$ & & $8(23.5 \%)$ & $7(20.5 \%)$ & \\
\hline Diabetes & $8(17.8 \%)$ & $6(13.0 \%)$ & & $6(17.6 \%)$ & $5(14.7 \%)$ & \\
\hline Chronic renal failure & $3(6.7 \%)$ & $2(4.3 \%)$ & & $1(2.9 \%)$ & $1(2.9 \%)$ & \\
\hline Other & $4(8.9 \%)$ & $1(2.2 \%)$ & & $2(5.9 \%)$ & $1(2.9 \%)$ & \\
\hline Histotype & & & 0.525 & & & 0.353 \\
\hline Intestinal & $31(72.1 \%)$ & $33(71.7 \%)$ & & $25(73.5 \%)$ & $23(67.6 \%)$ & \\
\hline Diffuse & $10(22.2 \%)$ & $12(26.1 \%)$ & & $6(17.6 \%)$ & $10(29.4 \%)$ & \\
\hline Mixte & $1(2.2 \%)$ & $0(0.0 \%)$ & & $0(0.0 \%)$ & $0(0.0 \%)$ & \\
\hline Other & $3(6.7 \%)$ & $1(2.2 \%)$ & & $3(8.8 \%)$ & $1(2.8 \%)$ & \\
\hline Tumor size (cm, mean, $\pm \mathrm{SD})$ & $4.1( \pm 1.8)$ & $4.4( \pm 2.1)$ & 0.693 & $4.1( \pm 1.9)$ & $4.0( \pm 2.2)$ & 0.899 \\
\hline
\end{tabular}


Table 2 Intraoperative and postoperative outcomes before and after propensity score matching analysis

\begin{tabular}{|c|c|c|c|c|c|c|}
\hline & \multicolumn{3}{|c|}{ Before propensity score matching } & \multicolumn{3}{|c|}{ After propensity score matching } \\
\hline & $\begin{array}{l}\text { ODG } \\
n=45\end{array}$ & $\begin{array}{l}\text { LDG } \\
n=46\end{array}$ & $p$ & $\begin{array}{l}\text { ODG } \\
n=34\end{array}$ & $\begin{array}{l}\text { LDG } \\
n=34\end{array}$ & $p$ \\
\hline Operative time (min, mean $\pm \mathrm{SD}$ ) & $199.8 \pm 61.6$ & $247.3 \pm 50.7$ & $<0.001$ & $197.2 \pm 66.4$ & $257.2 \pm 46.3$ & $<0.001$ \\
\hline Conversion $(n, \%)$ & & $5(10.8 \%)$ & & & $5(14,7)$ & \\
\hline Blood loss & $200.1 \pm 259.0$ & $153.8 \pm 256.2$ & 0.184 & $180.3 \pm 165.3$ & $140.8 \pm 170.9$ & 0.217 \\
\hline Time to bowel canalization (days, mean $\pm \mathrm{SD}$ ) & $5.8 \pm 1.8$ & $3.9 \pm 1.3$ & $<0.001$ & $5.6 \pm 1.5$ & $4.1 \pm 1.5$ & $<0.001$ \\
\hline Time to soft oral intake (days, mean $\pm \mathrm{SD}$ ) & $7.5 \pm 4.4$ & $4.7 \pm 1.4$ & $<0.001$ & $7.5 \pm 4.8$ & $4.8 \pm 1.5$ & $<0.001$ \\
\hline Length of stay (days, mean $\pm \mathrm{SD}$ ) & $15.2 \pm 12.6$ & $11.6 \pm 8.9$ & 0.073 & $15.8 \pm 13.7$ & $11.8 \pm 8.3$ & 0.120 \\
\hline Peri-operative complication ( $n$ pts, $\%$ ) & $16(35.6 \%)$ & $8(17.4 \%)$ & 0.084 & $10(29.4 \%)$ & $5(14.7 \%)$ & 0.144 \\
\hline \multicolumn{7}{|l|}{ Clavien-Dindo classification ( $n$ pts, \%) } \\
\hline I-II & $9(20.0 \%)$ & $5(10.9 \%)$ & 0.227 & $5(14.7 \%)$ & $5(14.7 \%)$ & 1.000 \\
\hline III-IV & $7(15.6 \%)$ & $3(6.5 \%)$ & 0.168 & $6(17.6 \%)$ & $2(5.9 \%)$ & 0.132 \\
\hline \multicolumn{7}{|l|}{ Postoperative complication $(n, \%)$} \\
\hline Anastomotic leakage & $1(2.2 \%)$ & $2(4.3 \%)$ & 0.984 & $1(2.9 \%)$ & $1(2.9 \%)$ & 0.473 \\
\hline Duodenal leakage & $4(8.9 \%)$ & $1(2.2 \%)$ & 0.344 & $3(8.8 \%)$ & $2(5.9 \%)$ & 0.642 \\
\hline Bleeding & $2(4.4 \%)$ & $1(2.2 \%)$ & 0.984 & $1(2.9 \%)$ & $1(2.9 \%)$ & 0.473 \\
\hline Canalization delay & $4(8.9 \%)$ & $0(0.0 \%)$ & 0.056 & $2(5.9 \%)$ & $2(5.9 \%)$ & 0.606 \\
\hline Cardiovascular & $1(2.2 \%)$ & $0(0.0 \%)$ & 0.494 & $1(2.9 \%)$ & $0(0.0 \%)$ & 0.500 \\
\hline Pulmonary & $3(6.7 \%)$ & $1(2.2 \%)$ & 0.593 & $2(5.9 \%)$ & $0(0.0 \%)$ & 0.119 \\
\hline Urinary & $0(0.0 \%)$ & $1(2.2 \%)$ & 0.505 & $0(0.0 \%)$ & $2(5.9 \%)$ & 0.119 \\
\hline Other & $2(4.4 \%)$ & $2(4.4 \%)$ & 0.624 & $2(5.9 \%)$ & $2(5.9 \%)$ & 0.606 \\
\hline Re-operation $(n, \%)$ & $7(15.6 \%)$ & $2(4.3 \%)$ & 0.073 & $6(17.6 \%)$ & $2(5.9 \%)$ & 0.132 \\
\hline Mortality $(n, \%)$ & $0(0.0 \%)$ & $1(2.2 \%)$ & 0.320 & $0(0.0 \%)$ & $1(2.9 \%)$ & 0.314 \\
\hline
\end{tabular}

matching analysis, the $\mathrm{N}$ stage was perfectly superimposable between the two groups $(p=1.000)$. Nonetheless, the number of metastatic lymph nodes $(5.6 \pm 5.9$ vs. $7.2 \pm 7.0, p=0.452)$ and lymph node ratio $(0.2 \pm 0.2$ vs. $0.3 \pm 0.3, p=0.216)$ were higher in the ODG group, even if not statistically significative.

Focusing on the long-term oncological outcomes, the median follow-up period was 31 months (range 0-116) months; the 5-year overall survival (OS) rate was $26.6 \%$ with a mean OS time of 46.2 \pm 5.5 months (95\% CI 35.4-57.0 months). The 5-year OS was $18.8 \%$ versus $45.8 \%, p=0.018$ (Fig. 2).

The 5-year disease-free survival (DFS) rate was $59.4 \%$ with a mean DFS time of $68.6 \pm 6.9$ months (95\% CI 55.1-82.1 months). The 5-year DFS was $34.4 \%$ versus $66.1 \%, p=0.044$ (Fig. 2).

\section{Post-hoc subgroups analysis}

We identified two subgroups for long-term outcomes analysis: the nodal status group and the TNM stage group. The first group accounted for $14(20.6 \%)$ patients with N0 disease and $54(79.4 \%)$ patients with $\mathrm{N}+$ disease. Each group had the same number of patients regarding the surgical approach (N0: 7 LDG vs 7 ODG; N+: 27 LDG vs. 27 ODG; $p=1.000$ ), resulting from the exact matching on $\mathrm{N}$ stage for the propensity score matching analysis. The TNM stage group had 32
(47.1\%) patients whit stage IB-II gastric cancer (20 LDG vs $12 \mathrm{ODG}$ ) and $36(52.9 \%$ ) with stage III disease (14 LDG vs 22 ODG); nonetheless, the difference between the two surgical approaches was not significant, $p=0.052$.

Concerning the nodal status subgroup, we observed statistically significant advantage of laparoscopic approach regarding both 5 -year OS $(71.4 \%$ vs. $0.0 \%, p=0.001)$ and DFS ( $100 \%$ vs. $57.1 \%, p=0.030)$ only for N0 patients, whereas survival curves for $\mathrm{N}+$ patients were comparable between the LDG and ODG: 5-year OS (28.0\% vs. $20.0 \%, p=0.242)$ and DFS (60.0\% vs. $48.0 \%, p=0.247)$ (Fig. 3$)$.

The same result appears in the TNM stage subgroup: stage IB-II patients had a better survival when treated by laparoscopy (5-year OS: $52.6 \%$ vs. $9.1 \%, p=0.002 ; 5$-year DFS $84.2 \%$ vs. $45.5 \%, p=0.005)$; although, the Kaplan -Meier's curves of the stage III patients were perfectly superimposable between the two groups (5-year OS: $15.4 \%$ vs. $19.0 \%, p=$ 0.985 ; 5-year DFS: $46.2 \%$ vs. $52.4 \%, p=0.724$ ) (Fig. 4).

\section{Discussion}

Since the publication of the results of the randomized controlled phase III "AIO-FLOT-4" trial, the gold standard of 
Table 3 Oncological outcomes before and after propensity score matching analysis

\begin{tabular}{|c|c|c|c|c|c|c|}
\hline & \multicolumn{3}{|c|}{ Before propensity score matching } & \multicolumn{3}{|c|}{ After propensity score matching } \\
\hline & $\begin{array}{l}\text { ODG } \\
n=45\end{array}$ & $\begin{array}{l}\text { LDG } \\
n=46\end{array}$ & $p$ & $\begin{array}{l}\text { ODG } \\
n=34\end{array}$ & $\begin{array}{l}\text { LDG } \\
n=34\end{array}$ & $p$ \\
\hline T-stage $(n, \%)$ & & & 0.743 & & & 0.589 \\
\hline pT1 & $0(0.0 \%)$ & $0(0.0 \%)$ & & $0(0.0 \%)$ & $0(0.0 \%)$ & \\
\hline pT2 & $13(28.9 \%)$ & $12(26.1 \%)$ & & $10(29.4 \%)$ & $9(26.5 \%)$ & \\
\hline pT3 & $17(37.8 \%)$ & $21(45.7 \%)$ & & $13(38.2 \%)$ & $17(50.0 \%)$ & \\
\hline pT4 & $15(33.3 \%)$ & $13(28.3 \%)$ & & $11(32.4 \%)$ & $8(23.5 \%)$ & \\
\hline N-stage $(n, \%)$ & & & 0.578 & & & 1.000 \\
\hline pN0 & $7(15.6 \%)$ & $12(26.1 \%)$ & & $7(20.6 \%)$ & $7(20.6 \%)$ & \\
\hline $\mathrm{pN} 1$ & $14(31.1 \%)$ & $16(34.8 \%)$ & & $8(23.5 \%)$ & $8(23.5 \%)$ & \\
\hline $\mathrm{pN} 2$ & $9(20.0 \%)$ & $8(17.4 \%)$ & & $9(26.5 \%)$ & $9(26.5 \%)$ & \\
\hline $\mathrm{pN} 3$ & $15(33.3 \%)$ & $10(21.7 \%)$ & & $10(29.4 \%)$ & $10(29.4 \%)$ & \\
\hline M-stage & & & 1.000 & & & 1.000 \\
\hline pM0 & $45(100 \%)$ & $46(100 \%)$ & & $34(100 \%)$ & $34(100 \%)$ & \\
\hline pM1 & $0(0.0 \%)$ & $0(0.0 \%)$ & & $0(0.0 \%)$ & $0(0.0 \%)$ & \\
\hline Retrieved nodes $(n)$ & & & 0.281 & & & 0.849 \\
\hline$($ mean $\pm \mathrm{SD})$ & $27.6 \pm 16.3$ & $24.6 \pm 10.3$ & & $26.1 \pm 12.3$ & $26.0 \pm 10.6$ & \\
\hline (median, range) & $24.0(2-94)$ & $24.5(5-54)$ & & $24.0(2-63)$ & $24.5(9-54)$ & \\
\hline Positive nodes (mean $\pm \mathrm{SD}$ ) & $8.8 \pm 12.8$ & $5.3 \pm 6.2$ & 0.102 & $7.2 \pm 7.0$ & $5.6 \pm 5.9$ & 0.452 \\
\hline Node ratio $($ mean $\pm \mathrm{SD})$ & $0.3 \pm 0.3$ & $0.2 \pm 0.2$ & 0.063 & $0.3 \pm 0.3$ & $0.2 \pm 0.2$ & 0.216 \\
\hline $\mathrm{R} 0$ resection $(n, \%)$ & $43(95.6 \%)$ & $45(97.8 \%)$ & 0.985 & $33(94.4 \%)$ & $34(100 \%)$ & 0.473 \\
\hline \multicolumn{7}{|l|}{ TNM stage $(n, \%)$} \\
\hline IA & $0(0.0 \%)$ & $0(0.0 \%)$ & 0.241 & $0(0.0 \%)$ & $0(0.0 \%)$ & 0.392 \\
\hline IB & $2(4.4 \%)$ & $4(8.7 \%)$ & & $2(5.9 \%)$ & $2(5.9 \%)$ & \\
\hline IIA & $6(13.3 \%)$ & $9(19.6 \%)$ & & $5(14.7 \%)$ & $6(17.6 \%)$ & \\
\hline IIB & $8(17.8 \%)$ & $15(32.6 \%)$ & & $5(14.7 \%)$ & $12(35.3 \%)$ & \\
\hline IIIA & $10(22.2 \%)$ & $4(8.7 \%)$ & & $8(23.5 \%)$ & $4(11.8 \%)$ & \\
\hline IIIB & $10(22.2 \%)$ & $7(15.2 \%)$ & & $7(20.6 \%)$ & $6(17.6 \%)$ & \\
\hline IIIC & $9(20.0 \%)$ & $7(15.2 \%)$ & & $7(20.6 \%)$ & $4(11.8 \%)$ & \\
\hline IV & $0(0.0 \%)$ & $0(0.0 \%)$ & & $0(0.0 \%)$ & $0(0.0 \%)$ & \\
\hline
\end{tabular}

treatment in Europe for locally advanced gastric cancer (stage IB-III) is radical gastrectomy with D2 lymphadenectomy and perioperative chemotherapy [4].

The minimally invasive approach, despite a longer operative time compared to open surgery, offers advantages in terms of blood loss, postoperative morbidity, faster recovery of intestinal function and oral intake, earlier mobilization, shorter hospitalization, and lower inflammatory response to intervention; all those elements probably contribute to a significant reduction in morbidity, especially related to medical causes [11, 13, 21-24].

Consequently, the Japanese gastric cancer treatment guidelines described, for the first time in 2014 (ver. 4), the LDG as one treatment option in general practice for stage I gastric cancer (T1N0M0, T1N1M0, or T2aN0M0) [3].

Recently, the results of the Korean KLASS-02, Japanese JLSSG0901, and Chinese CLASS-01 RCTs did not show any significant difference in terms of short-term efficacy between open and laparoscopic surgery in the treatment of locally advanced gastric cancer $[10,12,13]$.

This study confirmed a significant faster time of bowel canalization and oral intake for patients treated by laparoscopy and showed a favorable trend concerning the blood loss and the hospital stay for LDG group, even if statistical significance was not achieved.

Differences in postoperative morbidity and 30-day postoperative mortality were not seen between the two groups. The only death that occurred in the current series was due to a postoperative hemoperitoneum. The patient underwent reoperation by laparotomy but then developed heart failure.

Focusing on the postoperative morbidity, the patients treated by open approach developed a higher rate of major complications with the need of reoperation. 

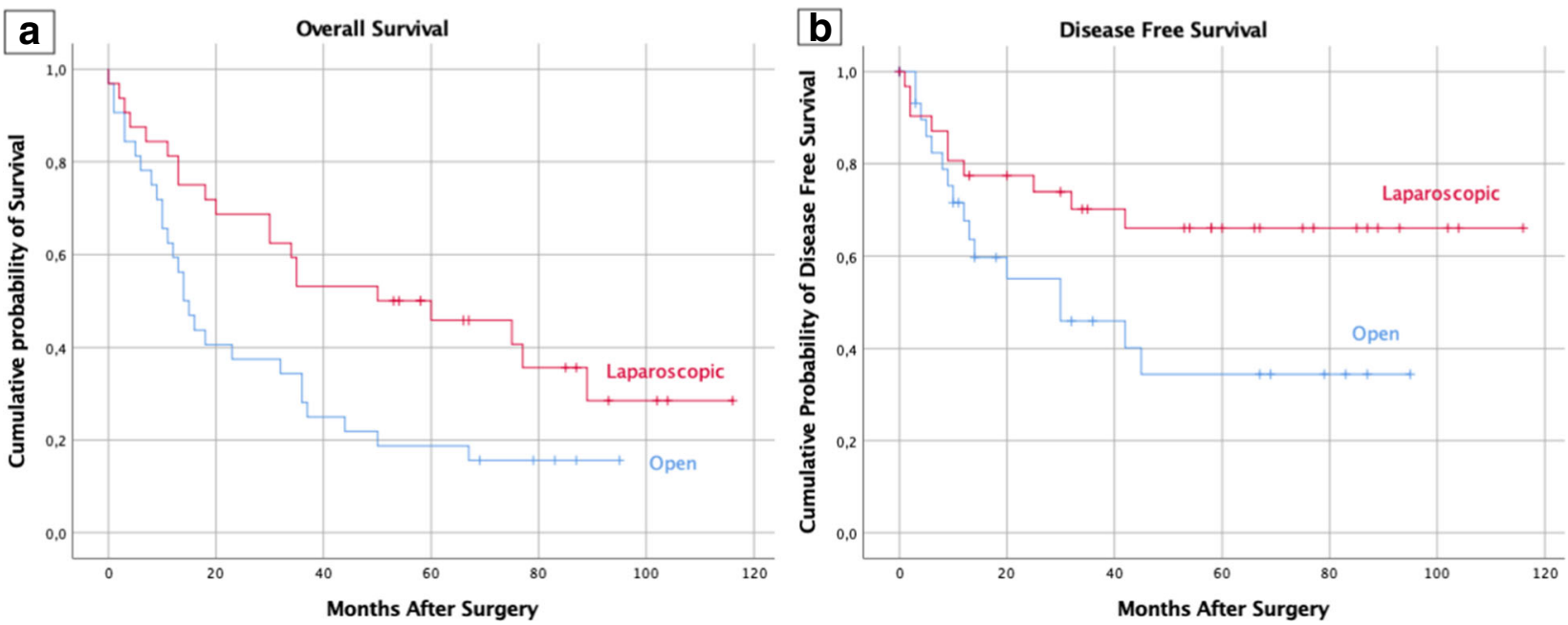

Number at risk

Laparoscopic

34
34

13
22

8
17

6

3
7

Number at risk

0 Open 34

0 Laparoscopic $34 \quad 22$

Fig. 2 a Patient's overall survival curves according to surgical approach. b Patient's disease-free survival curves according to surgical approach

Although the benefits of LDG in gastric cancer surgery are widely accepted, technical difficulty still represents the main concern of the surgeons [25]. LDG are currently performed by experienced surgeons in high-volume centers. Recently, the CRITICS trial results showed that high-volume centers $(\geq 21$ procedures per year) were associated with higher both overall and disease-free survival, emphasizing the value of centralizing gastric cancer surgeries in the Western world [14]. On the other hand, some Korean studies revealed that LDG in lowvolume centers is feasible and safe $[15,16]$. Interestingly, Kim et al. showed that the early surgical outcomes of LDG performed by the same surgeon in two different Korean hospital setting seems to be better when carried out in the high-volume center (> 1000 laparoscopic gastrectomies per year) [17].

In Italy, the minimum number of cases to define a highvolume center for gastric surgery is about $25-40$ cases per year, according to Italian Ministry of Health (www. oncoguida.it) and "Programma Nazionale Esiti (PNE)" [26], but no cut-off number of procedures per single surgeon has been established yet.

In our experience, surgery was performed by two oncological surgeons with large experience in open gastric surgery and laparoscopic surgery for colorectal cancer $[24,27-31]$. According to a literature review, the learning curve for LDG is not well defined, ranging from 20 up to 100 cases $[32,33]$.

Focusing on the extension of the lymph node dissection, nowadays the D2 lymphadenectomy with preservation of the pancreas and spleen is considered the standard of care by the guidelines of various global scientific societies $[34,35]$ and it is recommended to be conducted by an experienced surgeon, especially if performed laparoscopically $[6,7]$.
In general, laparoscopic D2 lymphadenectomy in locally advanced gastric cancer is believed to be more difficult to perform, as due to several limitations such as bulky tumor with a reduced exposure of the surgical field and determination of correct dissection plane, lesser degree of freedom, unsecure bleeding control, and easier tear of soft tissue [36].

In the current series, all patients underwent a D2 lymphadenectomy with preservation of the pancreas and spleen. The average number of lymph nodes removed was above the minimum number recommended by Japanese and Western guidelines [3, 4], showing how an expert laparoscopic surgeon can perform a D2 lymphadenectomy without any differences in extension and accuracy with open surgery [37].

The results of oncological outcomes showed a 5-year survival rate comparable with the European estimates $[1,2]$. When comparing the different surgical approaches, LDG showed an improved OS and disease-free survival DFS rate comparing to ODG. Possible biases such as age, comorbidities, histotype, and nodal stage were included as covariates in the propensity score matching analysis. The number of retrieved lymph nodes were comparable between the two groups, but the number of metastatic lymph nodes and the lymph node ratio were higher in the ODG group, even if not statistically significant.

In order to try to explain this surprising result, we identified two different subgroups analysis: nodal status $(\mathrm{N} 0, \mathrm{~N}+)$ and TNM stage.

Nodal stage has been established as an independent predictor of survival in several studies [38-40]; TNM stage by definition is associated with different survival rates. The classification of locally advanced gastric cancer includes a heterogeneous group of patients from stage IB to stage IIIC. 

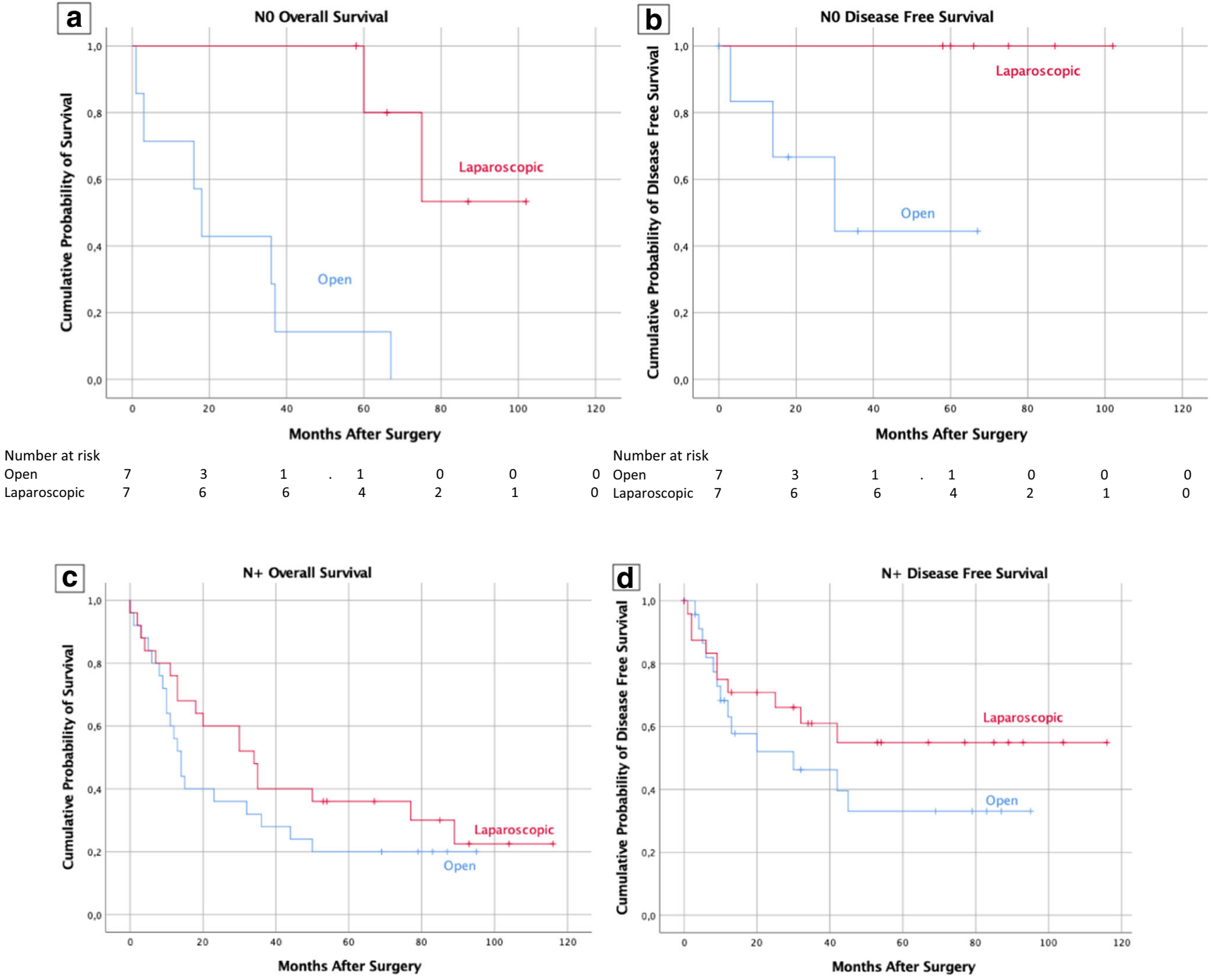

Number at risk

Open

Laparoscopic

27
27

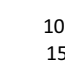

7
10

$\begin{array}{rl}5 & 3 \\ 7 & 5\end{array}$

$\begin{array}{ll} & \text { Numb } \\ 0 & \text { Open } \\ 0 & \text { Lapa }\end{array}$

umber at risk

Fig. 3 a, b Patient's overall and disease-free survival in patients with N0 gastric cancer according to surgical approach. c, d Patient's overall and diseasefree survival in patients with $\mathrm{N}+$ gastric cancer according to surgical approach

Consequently, it is often difficult to compare survival curves of such different patients.

The two subgroups of the current survival analysis were N0 vs. N+ and "early advanced" (stage IB-II) vs. "true advanced" (stage III). Basically, the cut-off stage was identified between stage IIB and IIIA.

The advantage of laparoscopic approach regarding the 5year OS and DFS was only confirmed in the NO and "early advanced" subgroups; conversely, N+ and stage III patients had superimposable survival curves.

This study has some limitations like the retrospective fashion of the study and the small sample size. However, despite these limitations, there are several important findings that are generated from this study and validated by the propensity score match analysis. This study confirms that laparoscopic surgery for locally advanced gastric adenocarcinoma is safe and effective, showing perioperative results similar to those obtained with the standard open technique.

To the best of our knowledge, this is the first report showing that 5-year OS and DFS of patients with N0 and "early advanced" gastric cancer can be positively influenced by the minimally invasive approach. Furthermore, the long-term oncological outcomes of patients with $\mathrm{N}+$ and "true advanced" disease were comparable as regarding LDG or ODG.

In conclusion, considering the low incidence of gastric cancer in Western countries, prospective studies are necessary to assess the safety of laparoscopic technique even in medium-low-volume centers. 



$\begin{array}{lllllll}\text { Number at risk } & & & & & & \\ \text { Open } & 22 & 8 & 5 & 4 & 3 & 0 \\ \text { Laparoscopic } & 14 & 5 & 3 & 3 & 1 & 0\end{array}$

Number at risk

$\begin{array}{llllllll}\text { Open } & 22 & 7 & 5 & 4 & 3 & 0 \\ \end{array}$

Fig. 4 a, b Patient's overall and disease-free survival in patients with stage IB-II gastric cancer according to surgical approach. $\mathbf{c}, \mathbf{d}$ Patient's overall and disease-free survival in patients with stage III gastric cancer according to surgical approach

Funding Information Open access funding provided by Università degli Studi di Roma La Sapienza within the CRUI-CARE Agreement.

\section{Compliance with ethical standard}

Conflict of interest The authors declare that they have no conflict of interest.

Ethical approval All procedures performed in studies involving human participants were in accordance with the ethical standards of the institutional and/or national research committee and with the 1964 Helsinki Declaration and its later amendments or comparable ethical standards. This article does not contain any studies with animals performed by any of the authors.

Informed consent Informed consent was obtained from all individual participants included in the study.

Open Access This article is licensed under a Creative Commons Attribution 4.0 International License, which permits use, sharing, adaptation, distribution and reproduction in any medium or format, as long as you give appropriate credit to the original author(s) and the source, provide a link to the Creative Commons licence, and indicate if changes were made. The images or other third party material in this article are included in the article's Creative Commons licence, unless indicated otherwise in a credit line to the material. If material is not included in the article's Creative Commons licence and your intended use is not permitted by statutory regulation or exceeds the permitted use, you will need to obtain permission directly from the copyright holder. To view a copy of this licence, visit http://creativecommons.org/licenses/by/4.0/.

\section{References}

1. Ferlay J, Steliarova-Foucher E, Lortet-Tieulent J, Rosso S, Coebergh JWW, Comber H et al (2013) Cancer incidence and mortality patterns in Europe: Estimates for 40 countries in 2012. Eur J Cancer

2. Bray F, Ferlay J, Soerjomataram I, Siegel RL, Torre LA, Jemal A (2018) Global cancer statistics 2018: GLOBOCAN estimates of 
incidence and mortality worldwide for 36 cancers in 185 countries. CA Cancer J Clin 68(6):394-424

3. Japanese gastric cancer treatment guidelines (2014) (ver. 4). Gastric cancer. 2017 Jan 1;20(1):1-19

4. Smyth EC, Verheij M, Allum W, Cunningham D, Cervantes A, Arnold D, ESMO Guidelines Committee (2016) Gastric cancer: ESMO clinical practice guidelines for diagnosis, treatment and follow-up. Ann Oncol 27:v38-v49

5. Songun I, Putter H, Kranenbarg EMK, Sasako M, van de Velde CJH (2010) Surgical treatment of gastric cancer: 15-year follow-up results of the randomised nationwide Dutch D1D2 trial. Lancet Oncol 11:439-449

6. Mocellin S, Mcculloch P, Kazi H, Gama-Rodrigues JJ, Yuan Y, Nitti D (2015) Extent of lymph node dissection for adenocarcinoma of the stomach. Cochrane Database Syst Rev

7. Wu CW, Hsiung CA, Lo SS, Hsieh MC, Chen JH, Li AFY, Lui WY, Whang-Peng J (2006) Nodal dissection for patients with gastric cancer: a randomised controlled trial. Lancet Oncol 7:309-315

8. Kitano S, Iso Y, Moriyama M (1994) Laparoscopy-assisted billroth I gastrectomy. Surg Laparosc Endosc

9. Nakamura K, Katai H, Mizusawa J, Yoshikawa T, Ando M, Terashima M, Ito S, Takagi M, Takagane A, Ninomiya M, Fukushima N, Sasako M (2013) A phase III study of laparoscopy-assisted versus open distal gastrectomy with nodal dissection for clinical stage IA/IB gastric cancer (JCOG0912). Jpn J Clin Oncol 43(3):324-327

10. Kim HH, Han SU, Kim MC, Kim W, Lee HJ, Ryu SW, Cho GS, Kim CY, Yang HK, Park DJ, Song KY, Lee SI, Ryu SY, Lee JH, Hyung WJ, for the Korean Laparoendoscopic Gastrointestinal Surgery Study (KLASS) Group (2019) Effect of laparoscopic distal Gastrectomy vs open distal Gastrectomy on long-term survival among patients with stage i gastric Cancer: the KLASS-01 randomized clinical trial. JAMA Oncol 5(4):506-513

11. Kim HH, Han SU, Kim MC, Hyung WJ, Kim W, Lee HJ et al (2013) Prospective randomized controlled trial (phase III) to comparing laparoscopic distal gastrectomy with open distal gastrectomy for gastric adenocarcinoma (KLASS 01). J Korean Surg Soc

12. Yu J, Huang C, Sun Y, Su X, Cao H, Hu J, Wang K, Suo J, Tao K, He X, Wei H, Ying M, Hu W, du X, Hu Y, Liu H, Zheng C, Li P, Xie J, Liu F, Li Z, Zhao G, Yang K, Liu C, Li H, Chen P, Ji J, Li G, for the Chinese Laparoscopic Gastrointestinal Surgery Study (CLASS) Group (2019) Effect of laparoscopic vs open distal gastrectomy on 3-year disease-free survival in patients with locally advanced gastric Cancer: the CLASS-01 randomized clinical trial. J Am Med Assoc 321(20):1983-1992

13. Lee S-W, Etoh T, Ohyama T, Inaki N, Sakuramoto S, Yoshida K et al (2017) Short-term outcomes from a multi-institutional, phase III study of laparoscopic versus open distal gastrectomy with D2 lymph node dissection for locally advanced gastric cancer (JLSSG0901). J Clin Oncol

14. Claassen YHM, van Amelsfoort RM, Hartgrink HH, Dikken JL, de Steur WO, van Sandick JW, et al. (2019) Effect of hospital volume with respect to performing gastric cancer resection on recurrence and survival: results from the CRITICS trial. Ann Surg [Internet]. [cited 2020 Jun 28];270(6):1096-102. Available from: https:// pubmed.ncbi.nlm.nih.gov/29995679/

15. Choi BS, Oh HK, Park SH, Park JM (2013) Comparison of laparoscopy-assisted and totally laparoscopic distal gastrectomy: the short-term outcome at a low volume center. J Gastric Cancer [Internet]. [cited 2020 Jun 28];13(1):44-50. Available from: https:// pubmed.ncbi.nlm.nih.gov/23610718/

16. Yang SJ, Ahn EJ, Park SH, Kim JH, Park JM (2010) The early experience of laparoscopy-assisted gastrectomy for gastric cancer at a low-volume center [Internet]. Vol. 10, J Gastric Cancer; [cited 2020 Jun 28]. p. 241-6. Available from: https://pubmed.ncbi.nlm. nih.gov/22076192/
17. Kim MG, Kwon SJ (2014) Comparison of the outcomes for laparoscopic gastrectomy performed by the same surgeon between a low-volume hospital and a high-volume center. Surg Endosc [Internet]. [cited 2020 Jun 28];28(5):1563-70. Available from: https://pubmed.ncbi.nlm.nih.gov/24380984/

18. La Torre M, Ferri M, Giovagnoli MR, Sforza N, Cosenza G, Giarnieri E, et al. (2010) Peritoneal wash cytology in gastric carcinoma. Prognostic significance and therapeutic consequences. Eur J Surg Oncol [Internet]. [cited 2020 Jun 27];36(10):982-6. Available from: https://pubmed.ncbi.nlm.nih.gov/20591604/

19. UICC (2009) TNM 7 th edition due December 2009. Union Int Cancer Control

20. Clavien PA, Barkun J, De Oliveira ML, Vauthey JN, Dindo D, Schulick RD et al (2009) The clavien-dindo classification of surgical complications: five-year experience. Ann Surg 250:187-196

21. Chen XZ, Hu JK, Yang K, Wang L, Lu QC (2009) Short-term evaluation of laparoscopy-assisted distal gastrectomy for predictive early gastric cancer: a meta-analysis of randomized controlled trials. Surg Laparosc Endosc Percutaneous Tech

22. Lee HJ, Hyung WJ, Yang HK, Han SU, Park YK, An JY, Kim W, Kim HI, Kim HH, Ryu SW, Hur H, Kong SH, Cho GS, Kim JJ, Park DJ, Ryu KW, Kim YW, Kim JW, Lee JH, Kim MC, Korean Laparo-endoscopic Gastrointestinal Surgery Study (KLASS) Group (2019) Short-term outcomes of a multicenter randomized controlled trial comparing laparoscopic distal gastrectomy with D2 lymphadenectomy to open distal gastrectomy for locally advanced gastric cancer (KLASS-02-RCT). Ann Surg 270(6):983991

23. Katai H, Mizusawa J, Katayama H, Takagi M, Yoshikawa T, Fukagawa T, Terashima M, Misawa K, Teshima S, Koeda K, Nunobe S, Fukushima N, Yasuda T, Asao Y, Fujiwara Y, Sasako M (2017) Short-term surgical outcomes from a phase III study of laparoscopy-assisted versus open distal gastrectomy with nodal dissection for clinical stage IA/IB gastric cancer: Japan clinical oncology group study JCOG0912. Gastric Cancer 20(4):699-708

24. Huscher CGS, Mingoli A, Sgarzini G, Sansonetti A, Di Paola M, Recher A et al (2005) Laparoscopic versus open subtotal gastrectomy for distal gastric cancer: five-year results of a randomized prospective trial. Ann Surg 241(2):232-237

25. Park JM, Jin SH, Lee SR, Kim H, Jung IH, Cho YK, Han SU (2008) Complications with laparoscopically assisted gastrectomy: multivariate analysis of 300 consecutive cases. Surg Endosc Other Interv Tech 22:2133-2139

26. Amato L, Fusco D, Acampora A, Bontempi K, Rosa AC, Colais P et al (2017) Volume and health outcomes: evidence from systematic reviews and from evaluation of Italian hospital data. Epidemiol Prev

27. Ceccarelli G, Pasculli A, Bugiantella W, De Rosa M, Catena F, Rondelli F, et al. (2020) Minimally invasive laparoscopic and robot-assisted emergency treatment of strangulated giant hiatal hernias: report of five cases and literature review [Internet]. Vol. 15, World journal of emergency surgery : WJES. NLM (Medline); [cited 2020 Jun 27]. p. 37. Available from: https://pubmed.ncbi. nlm.nih.gov/32487136/

28. Ceccarelli G, Costa G, Ferraro V, De Rosa M, Rondelli F, Bugiantella W (2020) Robotic or three-dimensional (3D) laparoscopy for right colectomy with complete mesocolic excision (CME) and intracorporeal anastomosis? A propensity score-matching study comparison. Surg Endosc [Internet]. [cited 2020 Jun 27]; Available from: https://pubmed.ncbi.nlm.nih.gov/32372219/

29. Masoni L, Mari FS, Nigri G, Favi F, Gasparrini M, Dall'Oglio A, et al. (2013) Preservation of the inferior mesenteric artery via laparoscopic sigmoid colectomy performed for diverticular disease: real benefit or technical challenge: a randomized controlled clinical trial. Surg Endosc [Internet]. [cited 2020 Jun 27];27(1):199-206. Available from: https://pubmed.ncbi.nlm.nih.gov/22733197/ 
30. Huscher CGS, Mingoli A, Sgarzini G, Brachini G, Binda B, Di Paola M, et al. (2007) Totally laparoscopic total and subtotal gastrectomy with extended lymph node dissection for early and advanced gastric cancer: early and long-term results of a 100-patient series. Am J Surg [Internet]. [cited 2020 Jun 27];194(6):839-44. Available from: https://pubmed.ncbi.nlm.nih.gov/18005781/

31. Lorenzon L, Mercantini P, Ferri M, La Torre M, Sparagna A, Balducci G, et al. (2014) Lymph-node ratio classification strongly correlates with cancer survivals of patients who underwent R0 resection for gastric cancer with more than 15 nodes harvested. Eur Surg Res [Internet]. [cited 2020 Jun 27];53(1-4):1-10. Available from: https://pubmed.ncbi.nlm.nih.gov/24854388/

32. Kim MC, Jung GJ, Kim HH (2005) Learning curve of laparoscopyassisted distal gastrectomy with systemic lymphadenectomy for early gastric cancer. World J Gastroenterol

33. Priego P, Cuadrado M, Ballestero A, Galindo J, Carda P, Lobo E (2019) Outcomes of the learning curve in our first 100 consecutive laparoscopic gastrectomies. Surg Laparosc Endosc Percutaneous Tech

34. Waddell T, Verheij M, Allum W, Cunningham D, Cervantes A, Arnold D (2013) Gastric cancer+: ESMO-ESSO-ESTRO clinical practice guidelines for diagnosis, treatment and follow-up. Ann Oncol 24:vi57-vi63

35. Garg PK, Jakhetiya A, Sharma J, Ray MD, Pandey D (2016) Lymphadenectomy in gastric cancer: contentious issues. World $\mathrm{J}$ Gastrointest Surg 8:294-300
36. Inaki N, Etoh T, Ohyama T, Uchiyama K, Katada N, Koeda K, Yoshida K, Takagane A, Kojima K, Sakuramoto S, Shiraishi N, Kitano S (2015) A multi-institutional, prospective, phase II feasibility study of laparoscopy-assisted distal gastrectomy with D2 lymph node dissection for locally advanced gastric cancer (JLSSG0901). World J Surg 39(11):2734-2741

37. Hayashi H, Ochiai T, Shimada H, Gunji Y (2005) Prospective randomized study of open versus laparoscopy-assisted distal gastrectomy with extraperigastric lymph node dissection for early gastric cancer. Surg Endosc Other Interv Tech

38. Mansour JC, Tang L, Shah M, Bentrem D, Klimstra DS, Gonen M et al (2007) Does graded histologic response after neoadjuvant chemotherapy predict survival for completely resected gastric cancer? Ann Surg Oncol

39. Gaca JG, Petersen RP, Peterson BL, Harpole DH, D'Amico TA, Pappas TN et al (2006) Pathologic nodal status predicts disease-free survival after neoadjuvant chemoradiation for gastroesophageal junction carcinoma. Ann Surg Oncol

40. Fujitani K, Mano M, Hirao M, Kodama Y, Tsujinaka T (2012) Posttherapy nodal status, not graded histologic response, predicts survival after neoadjuvant chemotherapy for advanced gastric cancer. Ann Surg Oncol 19:1936-1943

Publisher's note Springer Nature remains neutral with regard to jurisdictional claims in published maps and institutional affiliations. 